\title{
Transcatheter patent foramen ovale closure versus medical therapy for cryptogenic stroke: a meta-analysis of randomized clinical trials
}

Irbaz Bin Riaz', Abhijeet Dhoble², Ahmad Mizyed², Chiu-Hsieh Hsu³, Muhammad Husnain², Justin Z Lee', Kapildeo Lotun ${ }^{2}$ and Kwan S Lee $2^{2^{*}}$

\begin{abstract}
Background: There is an association between cryptogenic stroke and patent foramen ovale (PFO). The optimal treatment strategy for secondary prevention remains unclear. The purpose of this study was to analyze aggregate data examining the safety and efficacy of transcatheter device closure versus standard medical therapy in patients with PFO and cryptogenic stroke.

Methods: A search of published data identified 3 randomized clinical trials for inclusion. The primary outcome was a composite end-point of death, stroke and transient-ischemic attack (TIA). Pre-defined subgroup analysis was performed with respect to baseline characteristics including age, sex, atrial septal aneurysm and shunt size. Data was synthesized using a random effects model and results presented as hazard ratios (HRs) with 95\% confidence intervals (Cls).

Results: A cohort of 2,303 patients with a history of cryptogenic stroke and PFO were randomized to device closure $(n=1150)$ and medical therapy $(n=1153)$. Mean follow-up was 2.5 years. Transcatheter closure was not superior to medical therapy in the secondary prevention of stroke or TIA in intention-to-treat analysis (HR: 0.66, 95\% Cl: 0.43 to $1.01 ; p=0.056)$. However, the results were statistically significant using per-protocol analysis (HR: 0.64 , 95\% Cl: 0.41 to 0.98; $p=0.043)$. Males had significant benefit with device closure (HR: 0.48, 95\% Cl: 0.24 to 0.96; $\mathrm{p}=0.038)$.

Conclusions: In this meta-analysis, using intention-to-treat analysis, transcatheter device closure of PFO was not superior to standard medical therapy in the secondary prevention of cryptogenic stroke. Transcatheter closure was superior using per-protocol analysis.
\end{abstract}

Keywords: Patent foramen ovale, Inter atrial shunt, Transcatheter closure, Cryptogenic stroke

\section{Background}

It is believed that up to $30-40 \%$ of strokes are cryptogenic in nature [1-5]. Multiple observational studies have demonstrated an association between cryptogenic stroke and patent foramen ovale (PFO) [6-15]. The prevalence of PFO in the general community is around 25 to $30 \%$ of individuals based on autopsy and community based transesophageal echocardiography (TEE) studies [16,17]. The prevalence of PFO is about $60 \%$ in patients with cryptogenic strokes [18], supporting an etiological association.

\footnotetext{
* Correspondence: klee@shc.arizona.edu

${ }^{2}$ Department of Cardiovascular Diseases, University of Arizona, $3950 \mathrm{~S}$

Country Club Road, Suite 200, Tucson, AZ 85714, USA

Full list of author information is available at the end of the article
}

These associations suggest that paradoxical embolism may be the cause of stroke in some of these patients.

Most patients with cryptogenic stroke are less than 55 years of age with significant cost implications both in the short and long term [17,19-21]. The optimal treatment strategy of secondary prevention for patients with cryptogenic stroke is still unclear. To date, there have been several observational studies and three randomized trials evaluating the safety and efficacy of transcatheter closure versus medical therapy in reducing the risk of recurrent stroke in this patient population [22-24]. Two recent meta-analyses of observational studies favored transcatheter closure over medical therapy in preventing recurrent strokes $[25,26]$. However, observational studies 


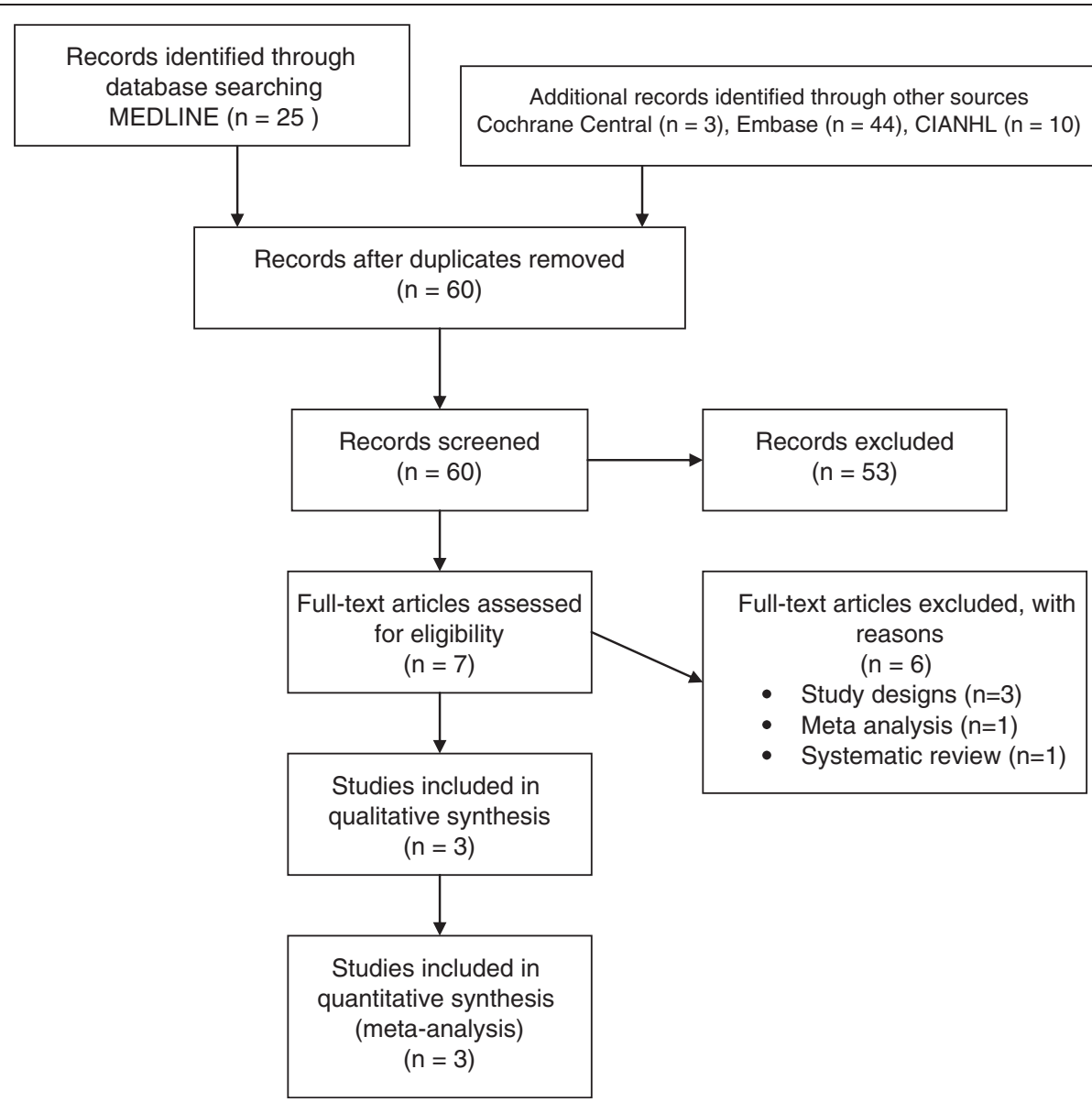

Figure 1 Flow diagram of trial selection process.

are limited by methodology and selection bias, whereas randomized trials provide the best scientific evidence for minimizing these biases. In this study, we only assessed the totality of evidence from the three recently published randomized trials on this subject. The main objectives of our meta-analysis were: 1) pool the aggregate data from these trials, thereby increasing the sample size and possibly reducing type 2 error; 2 ) explore the possibility of any particular sub-group that may derive benefit from the closure device; and 3) to assess the safety and complication rates of the procedure.

\section{Methods}

\section{Search strategy}

We searched Medline (via Ovid SP and PubMed), EMBASE, CINAHL and Cochrane Central Register For Controlled

Table 1 Summary of methodological assessment

\begin{tabular}{|c|c|c|c|c|c|}
\hline & $\begin{array}{l}\text { *Randomization } \\
\text { Method Described }\end{array}$ & $\begin{array}{l}* * \text { Allocation } \\
\text { concealment }\end{array}$ & $\begin{array}{c}\text { Blinding of participants, investigators, outcome } \\
\text { assessors and data assessors }\end{array}$ & $\begin{array}{l}* * * \text { Intention to } \\
\text { Treat Analysis }\end{array}$ & $\begin{array}{l}\text { Compliance } \\
\text { Checked }\end{array}$ \\
\hline CLOSURE & Yes & $\begin{array}{l}\text { Unclear but } \\
\text { probably yes }\end{array}$ & $\begin{array}{l}\text { Detailed information not clearly provided. Likely that } \\
\text { ascertainment of endpoint was unblinded. }\end{array}$ & Yes & Yes \\
\hline RESPECT & Yes & $\begin{array}{l}\text { Unclear but } \\
\text { probably yes }\end{array}$ & $\begin{array}{l}\text { Detailed information not clearly provided. Likely that } \\
\text { ascertainment of endpoint was unblinded. }\end{array}$ & Yes & Yes \\
\hline PC & Yes & $\begin{array}{l}\text { Unclear but } \\
\text { probably yes }\end{array}$ & Outcome and Data Assessors were blinded. & Yes & Yes \\
\hline
\end{tabular}


Table 2 Study characteristics and baseline characteristics of participants

\begin{tabular}{|c|c|c|c|c|c|c|}
\hline & \multicolumn{2}{|c|}{ CLOSURE } & \multicolumn{2}{|c|}{ PC } & \multicolumn{2}{|c|}{ RESPECT } \\
\hline \multicolumn{7}{|c|}{ Study Characteristics } \\
\hline Design & \multicolumn{2}{|c|}{ Randomized Controlled trial } & \multicolumn{2}{|c|}{ Randomized Controlled trial } & \multicolumn{2}{|c|}{ Randomized Controlled trial } \\
\hline Duration of follow up & \multicolumn{2}{|c|}{2.0 years } & \multicolumn{2}{|c|}{4.1 years } & \multicolumn{2}{|c|}{2.1 years } \\
\hline Location & \multicolumn{2}{|c|}{$\begin{array}{l}\text { Multi-center trial } \\
\text { (North America) }\end{array}$} & \multicolumn{2}{|c|}{$\begin{array}{l}\text { Multi-center trial } \\
\text { (Europe, Canada, Brazil, Australia) }\end{array}$} & \multicolumn{2}{|c|}{$\begin{array}{l}\text { Multi-center trial } \\
\text { (North America) }\end{array}$} \\
\hline \multirow[t]{3}{*}{ Total } & \multicolumn{2}{|c|}{909} & \multicolumn{2}{|c|}{414} & \multicolumn{2}{|c|}{980} \\
\hline & Closure & Medical & Closure & Medical & Closure & Medical \\
\hline & 447 & 462 & 204 & 210 & 499 & 481 \\
\hline \multicolumn{7}{|c|}{ Participants } \\
\hline Age & $46.3+/-9.6$ & $45.7+/-9.1$ & $44.3+/-10.2$ & $44.6+/-10.1$ & $45.7+/-9.7$ & $46.2+/-10.0$ \\
\hline Male sex & $52.1 \%$ & $51.5 \%$ & $45.1 \%$ & $54.3 \%$ & $53.7 \%$ & $55.7 \%$ \\
\hline \multicolumn{7}{|c|}{ Race or ethnic group } \\
\hline Asian & $1.6 \%$ & $1.7 \%$ & NA & NA & NA & NA \\
\hline Black & $4.2 \%$ & $5.6 \%$ & NA & NA & NA & NA \\
\hline White & $89.0 \%$ & $89.6 \%$ & NA & NA & NA & NA \\
\hline Hispanic & $6.7 \%$ & $4.8 \%$ & NA & NA & NA & NA \\
\hline Smoking during previous year & $21.5 \%$ & $22.6 \%$ & $22.5 \%$ & $22.4 \%$ & $15.0 \%$ & $11.4 \%$ \\
\hline Birth control/HRT & NA & NA & NA & NA & $8.2 \%$ & $10.8 \%$ \\
\hline Deep venous thrombosis & NA & NA & NA & NA & $4.0 \%$ & $3.1 \%$ \\
\hline \multicolumn{7}{|c|}{ Medical history (\%) } \\
\hline Hypertension & $33.8 \%$ & $28.4 \%$ & $24.0 \%$ & $27.6 \%$ & $31.7 \%$ & $31.2 \%$ \\
\hline Hypercholesterolemia & $47.4 \%$ & $40.9 \%$ & $24.5 \%$ & $29.5 \%$ & $38.9 \%$ & $40.1 \%$ \\
\hline Diabetes Mellitus & NA & NA & $2.5 \%$ & $2.9 \%$ & $6.6 \%$ & $8.3 \%$ \\
\hline Migraine & NA & NA & $23 \%$ & $18.1 \%$ & $39.1 \%$ & $38.5 \%$ \\
\hline $\begin{array}{l}\text { Family history of cardiovascular } \\
\text { disease or cerebrovascular accidents }\end{array}$ & $55.3 \%$ & $55.6 \%$ & $26.0 \%$ & $19.0 \%$ & $27.3 \%$ & $22.5 \%$ \\
\hline Congestive Heart Failure & $0.4 \%$ & $0 \%$ & NA & NA & $0.6 \%$ & $0 \%$ \\
\hline Ischemic heart disease & $1.3 \%$ & $0.9 \%$ & $2.0 \%$ & $1.9 \%$ & $3.8 \%$ & $1.9 \%$ \\
\hline Myocardial infarction & $1.6 \%$ & $1.1 \%$ & $1.5 \%$ & $0.5 \%$ & $1.0 \%$ & $0.4 \%$ \\
\hline Valvular dysfunction & $11.0 \%$ & $9.7 \%$ & $3.9 \%$ & $2.4 \%$ & NA & NA \\
\hline Arrhythmia & $5.8 \%$ & $4.1 \%$ & NA & NA & NA & NA \\
\hline Peripheral vascular disease & $1.1 \%$ & $1.5 \%$ & $1.5 \%$ & $1.0 \%$ & $1.0 \%$ & $0.2 \%$ \\
\hline Pulmonary embolus & 0 & $0.9 \%$ & NA & NA & NA & NA \\
\hline Peripheral embolism & NA & NA & $2.9 \%$ & $2.4 \%$ & NA & NA \\
\hline Previous TIA & NA & NA & NA & NA & $11.6 \%$ & $12.7 \%$ \\
\hline Previous Stroke & NA & NA & NA & NA & $10.6 \%$ & $10.6 \%$ \\
\hline \multicolumn{7}{|c|}{ Index neurologic event for study entry } \\
\hline Stroke & NA & NA & $80.9 \%$ & $77.6 \%$ & NA & NA \\
\hline Cryptogenic stroke & $72.6 \%$ & $71.4 \%$ & NA & NA & $100.0 \%$ & $100.0 \%$ \\
\hline TIA & $27.4 \%$ & $28.6 \%$ & $16.2 \%$ & $20.0 \%$ & NA & NA \\
\hline
\end{tabular}

Trials; for eligible studies with the terms "patent foramen ovale", "PFO", "heart septal defects (atrial)", "inter-atrial shunt", "atrial septal aneurysm", "ASA", "Transcatheter closure", "recurrent stroke", "recurrent TIA", "cryptogenic stroke" and "recurrent thromboembolism". In addition, abstracts and conference proceedings were hand searched where available. Reference lists from each article were scanned for further review. The search and extraction was performed according to the PRISMA statement [27]. 
Table 3 Summary of subgroup analysis

\begin{tabular}{|c|c|c|c|c|c|c|}
\hline \multirow[t]{2}{*}{ Subgroup } & \multicolumn{2}{|c|}{ CLOSURE Trial } & \multicolumn{2}{|c|}{ PC Trial } & \multicolumn{2}{|c|}{ RESPECT Trial } \\
\hline & Closure & Medical & Closure & Medical & Closure & Medical \\
\hline \multicolumn{7}{|c|}{ Sex (\%) } \\
\hline Male & 3.4 & 6.8 & NA & NA & 1.9 & 3.7 \\
\hline Female & 7.9 & 7.0 & NA & NA & 1.7 & 2.8 \\
\hline \multicolumn{7}{|c|}{ Atrial Septal Aneurysm (\%) } \\
\hline No & 6.2 & 7.4 & 1.9 & 5.7 & 2.2 & 2.2 \\
\hline Yes & 4.6 & 6.0 & 8.5 & 3.9 & 1.1 & 5.3 \\
\hline \multicolumn{7}{|c|}{ Age (\%) } \\
\hline$\leq 45 \mathrm{yr}$ & NA & NA & 1.1 & 6.2 & 1.7 & 2.4 \\
\hline$>45 \mathrm{yr}$ & NA & NA & 5.3 & 4.4 & 1.9 & 4.1 \\
\hline \multicolumn{7}{|c|}{ Cardiovascular index event (\%) } \\
\hline Stroke & 5.1 & 5.1 & 3.0 & 4.9 & NA & NA \\
\hline $\begin{array}{l}\text { TIA or } \\
\text { Peripheral } \\
\text { Embolism }\end{array}$ & 7.1 & 11.6 & 5.1 & 6.4 & NA & NA \\
\hline \multicolumn{7}{|c|}{ Shunt size (\%) } \\
\hline $\begin{array}{l}\text { None to } \\
\text { Moderate }\end{array}$ & 5.7 & 6.9 & NA & NA & 2.8 & 2.5 \\
\hline Substantial & 3.5 & 4.9 & NA & NA & 0.8 & 4.3 \\
\hline
\end{tabular}

\section{Study characteristics}

We searched all the databases for randomized controlled trials comparing medical therapy versus transcatheter closure of PFO for secondary prevention of cryptogenic stroke/TIA. In addition, a qualified reference librarian independently searched similar databases using the same search terms. Studies that met the eligibility criteria were included in the meta-analysis.

\section{Data collection}

Two independent investigators reviewed all articles for inclusion, with any disagreement resolved by consensus.
The reviewers independently extracted any variables that described the study population, intervention description, and outcome data. A structured template was used to extract the relevant data.

\section{Outcome measures}

The primary outcome was a composite of recurrent stroke, TIA or death during the mean follow up period of 2.5 years. Sub-group analysis was performed with respect to age, sex, atrial septal aneurysm and shunt size, where reported.

\section{Statistics}

Data from individual studies were pooled using a random effects model. Hazard Ratio (HR), reported with $95 \%$ confidence intervals $(\mathrm{CI})$ was used as a measure of effect with $\mathrm{HR}<1$ favoring device closure. A p-value of at least 0.05 was defined as statistically significant for the observed difference. Statistical heterogeneity was measured using Cochran's $Q$ statistic with $\alpha=0.05$ as well as the $\mathrm{I}^{2}$ statistic which is a measure of the proportion of the total variability due to heterogeneity beyond chance. $\mathrm{I}^{2}$ values of greater than $50 \%$ are consistent with significant heterogeneity.

\section{Results}

The results of the literature search are summarized in Figure 1. The COCHRANE search identified 3; Medline 25; EMBASE 44 and CINAHL 10 potentially eligible trials. Review of conference abstracts and reference lists did not identify any additional trials. Using a wellformulated search strategy (Additional file 1), a total of 60 records (after removing duplicates) were screened for inclusion in the meta-analysis. Three randomized controlled trials met our inclusion criteria and were included in the final analysis. The CLOSURE I Trial was a large, multi-center, randomized, clinical trial in which a

Table 4 Summary of adverse events/complications

\begin{tabular}{|c|c|c|c|c|c|c|}
\hline \multirow{2}{*}{ Event } & \multicolumn{2}{|c|}{ CLOSURE Trial } & \multicolumn{2}{|c|}{ PC Trial } & \multicolumn{2}{|c|}{ RESPECT Trial } \\
\hline & Closure & Medical therapy & Closure & Medical therapy & Closure & Medical therapy \\
\hline Major vascular procedural complication (\%) & 3.2 & NA & 1.5 & NA & 0.6 & NA \\
\hline Atrial fibrillation (\%) & 5.7 & 0.7 & 2.9 & 1.0 & 3.0 & $1.5 \%$ \\
\hline Major bleeding episode (\%) & 2.6 & 1.1 & 3.9 & 5.7 & 1.6 & 1.9 \\
\hline Death other than end point (\%) & 0.5 & 0.9 & NA & NA & NA & NA \\
\hline Nervous system disorder (\%) & 1.5 & 3.5 & NA & NA & NA & NA \\
\hline PFO-related hospital admission (\%) & NA & NA & 6.4 & 6.2 & NA & NA \\
\hline Dizziness (\%) & NA & NA & 0.5 & 1.9 & NA & NA \\
\hline Seizure (\%) & NA & NA & 0.5 & 1.4 & NA & NA \\
\hline Dyspnea (\%) & NA & NA & 0 & 1.9 & NA & NA \\
\hline Chest pain (\%) & NA & NA & 1.5 & 1.9 & NA & NA \\
\hline Allergic drug reaction (\%) & NA & NA & 0.5 & 1.0 & 0.2 & NA \\
\hline
\end{tabular}


Table 5 Primary endpoint meta-analysis

\begin{tabular}{|c|c|c|c|c|c|c|c|c|c|}
\hline \multirow[t]{2}{*}{ Endpoint } & \multicolumn{2}{|c|}{ Closure Trial } & \multicolumn{2}{|c|}{ PC Trial } & \multicolumn{2}{|c|}{ Respect Trial } & \multicolumn{3}{|c|}{ Random Effects Model } \\
\hline & $\mathrm{HR}$ & $95 \% \mathrm{Cl}$ & $\mathrm{HR}$ & $95 \% \mathrm{Cl}$ & $\mathrm{HR}$ & $95 \% \mathrm{Cl}$ & $\mathrm{HR}$ & $95 \% \mathrm{Cl}$ & p-value \\
\hline \multicolumn{10}{|c|}{ ITT Population } \\
\hline Composite endpoint of all devices & 0.78 & $0.45,1.35$ & 0.63 & $0.24,1.62$ & 0.49 & $0.22,1.11$ & 0.66 & $0.43,1.01$ & 0.06 \\
\hline Composite endpoint of Amplatzer device & & & 0.63 & $0.24,1.62$ & 0.49 & $0.22,1.11$ & 0.54 & $0.29,1.01$ & 0.05 \\
\hline \multicolumn{10}{|c|}{ Per Protocol } \\
\hline Composite endpoint of all devices & 0.74 & $0.42,1.29$ & 0.70 & $0.27,1.85$ & 0.37 & $0.14,0.96$ & 0.64 & $0.41,0.98$ & 0.04 \\
\hline Composite endpoint of Amplatzer device & & & 0.70 & $0.27,1.85$ & 0.37 & $0.14,0.96$ & 0.64 & $0.44,0.97$ & 0.03 \\
\hline
\end{tabular}

total of 909 patients were enrolled between June 2003, and October 2008, utilizing the STARFlex device. The Amplatzer PFO closure device was studied in both the PC Trial, a multi-center, randomized trial performed in Europe, Canada, Brazil and Australia, enrolling 414 patients over 9 years; and RESPECT, a large, US multicenter trial enrolling 980 patients from August 2003 to December 2011. The results and methodological quality of the 3 trials are summarized in Table 1. All trials had excellent randomization procedures, and intention-totreat analyses were reported for primary outcomes. Methods for allocation concealment were not clearly described. Although the adjudication of the end point was blinded, ascertainment of end points was probably unblinded except in the RESPECT trial. There was no significant heterogeneity present amongst trials $\left(\mathrm{I}^{2}<50\right)$.

A total of 2303 patients with a prior history of cryptogenic stroke were randomized; 1150 to device closure and 1153 to medical therapy. The study characteristics and baseline characteristics of the participants are summarized in Table 2. We found that transcatheter closure was not superior to standard medical treatment in the secondary prevention of strokes/TIA in patients with a PFO during a mean period of 2.5 years (maximum, 7 years) according to intention to treat analysis (HR 0.66, 95\% CI 0.43-1.01, $\mathrm{p}=0.056$ ), with a trend favoring device closure. When analyzed using per-protocol method, transcatheter closure was superior to standard medical therapy in preventing recurrent events (HR: 0.64, 95\% CI: $0.41-0.98 ; \mathrm{p}=0.043)$. Interestingly, we found that in the male population, reported in CLOSURE 1 and RESPECT, device closure was significantly associated with a reduction of recurrent events even with intention-to-treat analysis (HR 0.48, 95\% CI 0.24-0.96, p = 0.038). No other subgroup clearly benefitted from device closure. Our analysis failed to confirm the benefit of transcatheter closure in patients with atrial septal aneurysm. The details of subgroup analysis are described in Table 3. The complication rates from transcatheter closure and medical treatment are summarized in Table 4. Major bleeding rates were similar in both groups, but atrial fibrillation occurred more often in the device group (HR 3.43, 95\% CI 1.17-10.00, $\mathrm{p}=0.024$ ). The meta-analysis and forest plots are shown in Tables 5, 6 and 7 and Figures 2, 34 and 5 respectively.

Table 6 Subgroup analysis of the primary endpoint

\begin{tabular}{|c|c|c|c|c|c|c|c|c|c|}
\hline \multirow[t]{2}{*}{ Subgroup } & \multicolumn{2}{|c|}{ Closure Trial } & \multicolumn{2}{|c|}{ PC Trial } & \multicolumn{2}{|c|}{ Respect Trial } & \multicolumn{3}{|c|}{ Random Effects Model } \\
\hline & $\mathrm{HR}$ & $95 \% \mathrm{Cl}$ & $\mathrm{HR}$ & $95 \% \mathrm{Cl}$ & $\mathrm{HR}$ & $95 \% \mathrm{Cl}$ & HR & $95 \% \mathrm{Cl}$ & p-value \\
\hline \multicolumn{10}{|c|}{ Atrial Septal Aneurysm } \\
\hline Yes & 0.78 & $0.30,2.13$ & 2.09 & $0.38,11.4$ & 0.19 & $0.04,0.87$ & 0.67 & $0.21,2.16$ & 0.50 \\
\hline No & 0.81 & $0.42,1.59$ & 0.32 & $0.09,1.18$ & 0.89 & $0.31,2.54$ & 0.71 & $0.43,1.19$ & 0.19 \\
\hline \multicolumn{10}{|c|}{ Age } \\
\hline$\leq 45$ & NA & NA & 0.16 & $0.02,1.31$ & 0.70 & $0.19,2.60$ & 0.42 & $0.11,1.66$ & 0.22 \\
\hline$>45$ & NA & NA & 1.22 & $0.37,3.99$ & 0.41 & $0.14,1.17$ & 0.68 & $0.23,2.00$ & 0.48 \\
\hline \multicolumn{10}{|c|}{ Sex } \\
\hline Male & 0.50 & $0.20,1.22$ & NA & NA & 0.45 & $0.15,1.31$ & 0.48 & $0.24,0.96$ & 0.04 \\
\hline Female & 1.13 & $0.55,2.34$ & NA & NA & 0.57 & $0.16,2.02$ & 0.96 & $0.51,1.79$ & 0.89 \\
\hline \multicolumn{10}{|c|}{ Shunt Size } \\
\hline None, trace or moderate & 0.78 & $0.40,1.50$ & NA & NA & 1.03 & $0.35,3.08$ & 0.84 & $0.48,1.49$ & 0.56 \\
\hline Substantial & 0.72 & $0.15,3.57$ & NA & NA & 0.18 & $0.04,0.81$ & 0.35 & $0.09,1.39$ & 0.14 \\
\hline
\end{tabular}


Table 7 Meta-analysis of adverse events or complications

\begin{tabular}{|c|c|c|c|c|c|c|c|c|c|}
\hline \multirow{2}{*}{$\begin{array}{l}\text { Complications - } \\
\text { no./total no. }\end{array}$} & \multicolumn{2}{|c|}{ Closure trial } & \multicolumn{2}{|c|}{ PC trial } & \multicolumn{2}{|c|}{ Respect trial } & \multicolumn{3}{|c|}{ Random effects model } \\
\hline & Device & Medical & Device & Medical & Device & Medical & OR & $95 \% \mathrm{Cl}$ & p-value \\
\hline Major bleeding & $10 / 378$ & $4 / 374$ & $7 / 204$ & $12 / 210$ & $8 / 499$ & $9 / 481$ & 1.02 & $0.46,2.27$ & 0.97 \\
\hline Atrial fibrillation & $23 / 402$ & $3 / 458$ & $5 / 204$ & $2 / 210$ & $15 / 499$ & $8 / 481$ & 3.43 & $1.17,10.00$ & 0.02 \\
\hline
\end{tabular}

\section{Discussion}

In this meta-analysis, we analyzed and reported aggregate data for adult patients with PFO and cryptogenic stroke from three large randomized trials comparing standard medical therapy versus transcatheter closure [22-24]. Our study is limited by the heterogeneity of data available from these three clinical trials, such as type of devise used for closure, drugs used for medical therapy, patient population, geographic location within the small number of included trials, particularly with regards the CLOSURE 1 trial. The Starflex closure device employed in the trial, as compared to the Amplatzer device in PC and RESPECT has since been discontinued, partially due to the high device complication rate reported in CLOSURE 1 and association of the device towards the later development of atrial fibrillation $(5.7 \%$ vs. $0.7 \%, \mathrm{p}<0.001)$, thrombosis and mechanical complications, all possible contributor towards recurrent stroke. Similarly, the rate of successful PFO closure was $89.4 \%$ in the CLOSURE I trial, as compared to a very high success rate of more than $96 \%$ in the PC and RESPECT trials, suggesting superiority of the Amplatzer device compared to the STARFlex device. Furthermore, the definition of neurological event inclusion criteria was not as strict in CLOSURE 1 and did not mandate MRI neuro-radiological evidence of an ischemic event in the setting of TIA. Follow-up was shorter than in PC and RESPECT ( 2 years vs. 4.1 and 2.6 years), which may have decreased the ability to detect a treatment effect due to the relative rarity of recurrent TIA or strokes. These events may have only been observed with longer

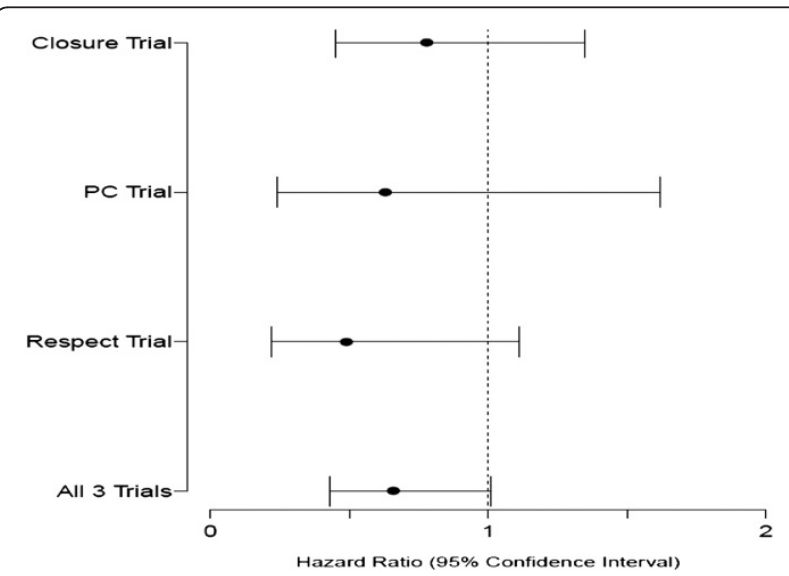

Figure 2 Forest plot showing intention-to-treat analysis of primary end point for all three randomised clinical trials. follow-up. We report analysis of aggregate data from three RCTs, but meta-analysis of individual patient data may provide clear and better understanding of the benefit of one treatment modality over other. Due to the unavailability of individual patient data, we could not analyze adverse events in detail.

Despite ambiguity regarding patient selection, less than optimum patient enrollment, and inadequate follow up, our meta-analyses which combined data from the three RCTs showed a trend towards superiority of PFO closure as compared to medical therapy, and statistically significant benefit of PFO closure in the per protocol population. Similar results were found when the Amplatzer PFO device was analyzed in the RESPECT trial after accounting for an unequal drop-out rate with perprotocol and as-treated method, which then demonstrated significant benefit with device closure. Likewise, results from the underpowered PC trial (414 patients) were not-statistically significant but the trend for the end-point of stroke and TIA uniformly favored the Amplatzer device.

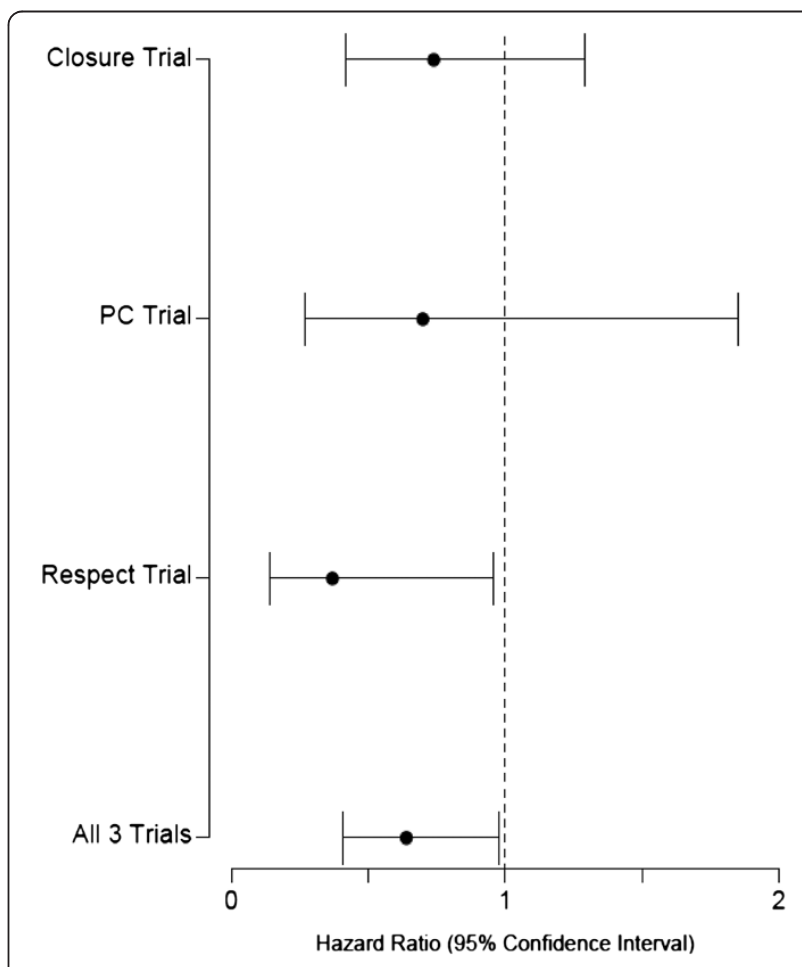

Figure 3 Forest Plot showing per-protocol analysis of primary end points for all three randomised clinical trials. 


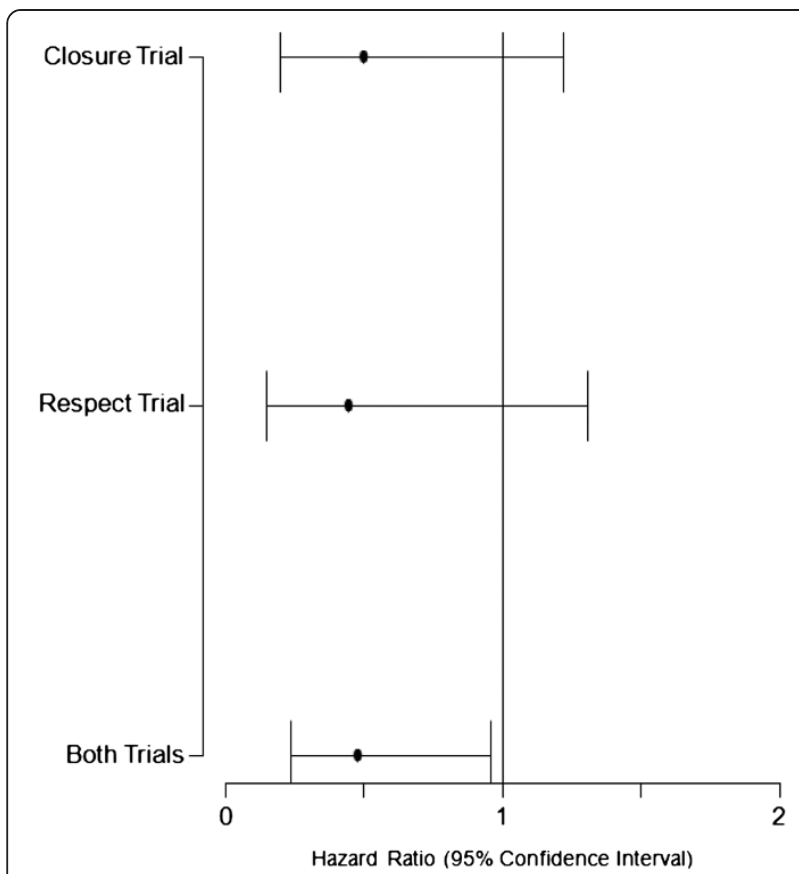

Figure 4 Forest plot showing subgroup analysis of primary end point for male population (CLOSURE and RESPECT Trial).

Case-series and retrospective analyses of patients with PFO and cryptogenic stroke have previously suggested that transcatheter closure of PFO for prevention of recurrent stroke is a highly efficacious and safe procedure [28-32]. Two recent meta-analyses of observational

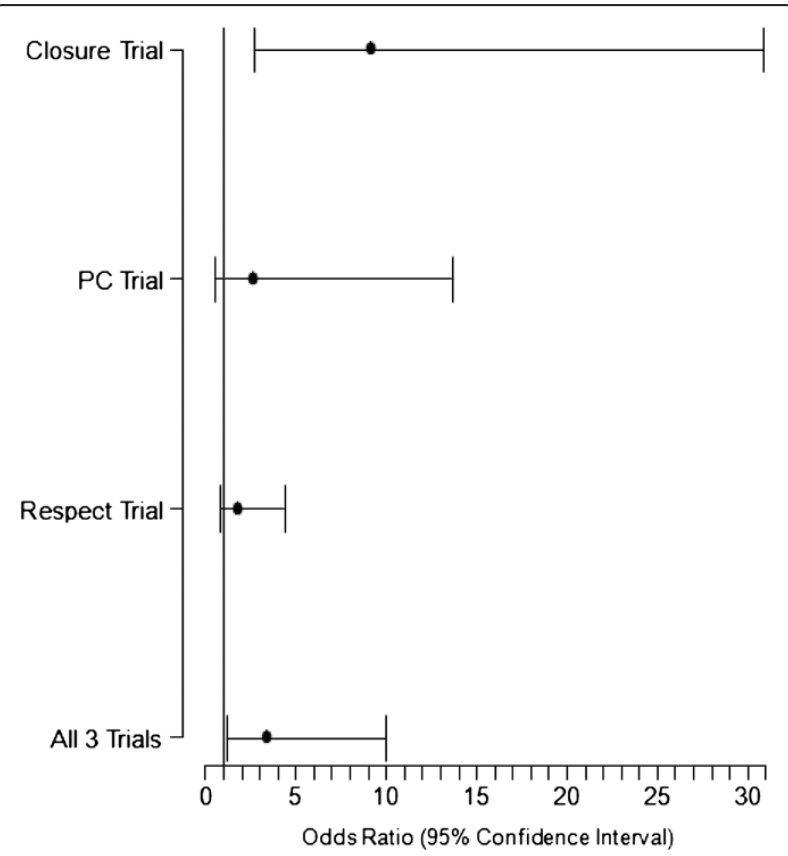

Figure 5 Forest plot showing analysis of atrial fibrillation in all three clinical trials. studies showed that transcatheter closure was superior to medical management, with the incidence of recurrent strokes being more than 6 times higher in medically treated patients than those who underwent transcatheter closure $[25,26]$. The number of patients reported in observational studies were at least 8 -fold larger than the total number of patients enrolled in the three RCTs. Similarly, over 15,000 closure procedures have been reported in the literature in observation studies or case series, as compared to only 1,103 patients reported in RCTs. This could be due to rapid adoption of this intervention by many clinical practitioners due to the observation that transcatheter closure is a safe and effective procedure. There are several features about the three randomized trials that are worth considering: all the trials included relatively younger patients with cryptogenic strokes and TIAs. The outcome rate in patients receiving medical therapy was lower compared to published observational studies in the literature, suggesting that the baseline risk in the trial population may have been lower. This may point to a failure to appropriately select patients in the clinical trials who were more likely to have had PFO-related events, possibly attributable to the preference of patients to undergo PFO closure coupled with the reluctance of physicians to randomize patients with true PFO related cryptogenic stroke, such as the ones with clinical indicators of paradoxical embolism (e.g. very large shunt, associated atrial septal aneurysm), or absence of any conventional stroke risk factors. These patients then could have been preferentially treated with off-protocol transcatheter closure. This hypothesis is strongly supported by the findings from a study by the Cleveland Clinic, which indicates that offlabel PFO closures out-numbered patient recruitment into the CLOSURE I trial by 3:1 at their institution during the study recruitment period (32). They also found that the large shunts were considerably more common in off-label patients, suggesting that higher-risk patients may have been favorably closed off-label. On the other hand, outcome rates in the closure group, especially in the CLOSURE I trial were higher compared to previous estimates from observational studies.

One can also argue that the benefits of transcatheter closure may become apparent only with longer followup, as this intervention is expected to prevent the occurrence of a relatively rare clinical outcome. The 2 to 4 years of follow-up may be inadequate to fully capture the benefit of PFO closure. A study with a long followup of up to 15 years, showed that percutaneous PFO closure appeared equally effective for secondary stroke prevention $(0.59(0.26-1.34) \mathrm{p}=0.21)$ and more effective for secondary TIA prevention $(0.19(0.08-0.49) \mathrm{p}=0.001)$ compared with medical treatment in patients with $\mathrm{PFO}$ [33]. PFO closure studies such as CryptoCard (Trials 
register \#NCT01018355) have been terminated due to dissatisfactory enrollment rate.

It is important to recognize difficulties encountered in enrollment of patients in such trials and the possibility that results from three individual RCTs may make it even more difficult to enroll sufficient patients in the future to detect an event with a very low clinical rate. We await the results of 3 ongoing large randomized trials (REDUCE, CLOSE, and DEFENSE-PFO), which aim to study the relative benefit of anticoagulation, antiplatelet and transcatheter device closure with the Amplatzer and GORE Septal Occluder.

\section{Conclusions}

The results of our meta-analysis show a favorable trend towards transcatheter closure of PFO as compared to medical therapy in intention-to-treat analysis and confirm a benefit in per-protocol analysis, despite the fact that many patients who would have truly benefited from device closure may have not been randomized in these trials, but underwent off-label closure. Device-related complications were higher with the STARFlex device compared to the Amplatzer device, with atrial fibrillation being the most frequent complication. A significant benefit of transcatheter PFO closure was apparent in male patients. Based on current evidence, it is premature to conclude that transcatheter closure of a PFO is futile in cryptogenic stroke, and we therefore advocate continued randomization of future patients in ongoing trials designed to answer the question. Our finding of possible increased selective benefit in males is hypothesis generating and may deserve specific study.

\section{Additional file}

Additional file 1: Search Strategy.

\begin{abstract}
Abbreviations
PFO: Patent foramen ovale; TIA: Transient ischemic attack;

TEE: Transesophageal echocardiography; CLOSURE I: Evaluation of the STARFlex septal closure system in patients with a stroke and/or transient ischemic attack due to presumed paradoxical embolism through a patent foramen ovale; PC: Clinical trial comparing percutaneous closure of patent foramen ovale using the amplatzer PFO occluder with medical treatment in patients with cryptogenic embolism; RESPECT: Randomized evaluation of recurrent stroke comparing PFO closure to established current standard of care treatment.
\end{abstract}

\section{Competing interests}

No significant competing interests present.

\section{Authors' contributions}

IR MD: Conception and design, analysis and interpretation of data, drafting of manuscript. AD MD: Conception and design, analysis and interpretation of data, drafting of manuscript, revising critically for important intellectual content. AM MD: Drafting of manuscript. CHH PhD: Conception and design, analysis and interpretation of data. MH MD: Analysis and interpretation of data, drafting of manuscript. JZL MD: Analysis and interpretation of data, drafting of manuscript. KL MD: Revising critically for important intellectual content, final approval of manuscript submitted. KSL MD: Conception and design; analysis and interpretation of data, drafting of manuscript, revising critically for important intellectual content, final approval of manuscript submitted. All authors read and approved the final manuscript.

\section{Author details}

${ }^{1}$ Department of Internal Medicine, University of Arizona, Tucson, AZ 85714, USA. ${ }^{2}$ Department of Cardiovascular Diseases, University of Arizona, $3950 \mathrm{~S}$ Country Club Road, Suite 200, Tucson, AZ 85714, USA. ${ }^{3}$ Department of Biostatistics, University of Arizona, Tucson, AZ 85714, USA.

Received: 9 September 2013 Accepted: 6 December 2013

Published: 11 December 2013

\section{References}

1. Petty GW, Brown RD, Whisnant JP, Sicks JRD, O'Fallon WM, Wiebers DO: Ischemic stroke subtypes: a population-based study of incidence and risk factors. Stroke 1999, 30(12):2513-2516.

2. Kolominsky-Rabas PL, Weber M, Gefeller O, Neundoerfer B, Heuschmann PU: Epidemiology of ischemic stroke subtypes according to TOAST criteria incidence, recurrence, and long-term survival in ischemic stroke subtypes: a population-based study. Stroke 2001, 32(12):2735-2740.

3. Schulz UG, Rothwell PM: Differences in vascular risk factors between etiological subtypes of ischemic stroke: importance of population-based studies. Stroke 2003, 34(8):2050-2059.

4. Schneider AT, Kissela B, Woo D, Kleindorfer D, Alwell K, Miller R, Szaflarski J, Gebel J, Khoury J, Shukla R: Ischemic stroke subtypes A population-based study of incidence rates among blacks and whites. Stroke 2004, 35(7):1552-1556.

5. Lee Bl, Nam HS, Heo JH, Kim DI: Yonsei stroke registry. Cerebrovasc Dis 2001, 12(3):145-151.

6. De Castro S, Cartoni D, Fiorelli M, Rasura M, Anzini A, Zanette EM, Beccia M, Colonnese C, Fedele F, Fieschi C: Morphological and functional characteristics of patent foramen ovale and their embolic implications. Stroke 2000, 31(10):2407-2413.

7. Mas $J$, Zuber M: Recurrent cerebrovascular events in patients with patent foramen ovale, atrial septal aneurysm, or both and cryptogenic stroke or transient ischemic attack. Am Heart J 1995, 130(5):1083-1088.

8. Bogousslavsky J, Garazi S, Jeanrenaud X, Aebischer N, Van Melle G, On behalf of Lausanne Stroke with Paradoxal Embolism Study Group: Stroke recurrence in patients with patent foramen ovale: the Lausanne Study. Neurology 1996, 46:1301-1305.

9. Cabanes L, Mas J, Cohen A, Amarenco P, Cabanes P, Oubary P, Chedru F, Guerin F, Bousser M, De Recondo J: Atrial septal aneurysm and patent foramen ovale as risk factors for cryptogenic stroke in patients less than 55 years of age. A study using transesophageal echocardiography. Stroke 1993, 24(12):1865-1873.

10. Comess KA, DeRook FA, Beach KW, Lytle NJ, Golby AJ, Albers GW: Transesophageal echocardiography and carotid ultrasound in patients with cerebral ischemia: prevalence of findings and recurrent stroke risk. J Am Coll Cardiol 1994, 23(7):1598-1603.

11. Di Tullio M, Sacco RL, Gopal A, Mohr J, Homma S: Patent foramen ovale as a risk factor for cryptogenic stroke. Ann Int Med 1992, 117(6):461.

12. Homma S, Sacco RL, Di Tullio MR, Sciacca RR, Mohr J: Effect of medical treatment in stroke patients with patent foramen ovale. Circulation 2002, 105(22):2625-2631.

13. Lechat P, Lascault G, Mas J, Loron P, Klimczac K, Guggiari M, Drobinski G, Fraysse J, Thomas D, Grosgogeat Y: Prevalence of patent foramen ovale in young patients with ischemic cerebral complications]. Arch des Maladies du coeur et des vaisseaux 1989, 82(6):847.

14. Mas JL, Arquizan C, Lamy C, Zuber M, Cabanes L, Derumeaux G, Coste J: Recurrent cerebrovascular events associated with patent foramen ovale, atrial septal aneurysm, or both. N Engl J Med 2001, 345(24):1740-1746.

15. Webster M, Smith H, Sharpe D, Chancellor A, Swift D, Bass N, Glasgow G: Patent foramen ovale in young stroke patients. Lancet 1988, 332(8601):11-12.

16. Meissner I, Whisnant JP, Khandheria BK, Spittell PC, O'Fallon WM, Pascoe RD, Enriquez-Sarano M, Seward JB, Covalt JL, Sicks JRD, Wiebers DO: Prevalence of potential risk factors for stroke assessed by transesophageal echocardiography and carotid ultrasonography: the SPARC study. Mayo Clin Proc 1999, 74(9):862-869. 
17. Hagen PT, Scholz DG, Edwards WD: Incidence and size of patent foramen ovale during the first 10 decades of life: an autopsy study of 965 normal hearts. Mayo Clinic Proc 1984, 59(1):17-20.

18. Khairy P, O'Donnell CP, Landzberg MJ: Transcatheter closure versus medical therapy of patent foramen ovale and presumed paradoxical thromboemboli: a systematic review. Ann Intern Med 2003, 139(9):753-760

19. Kristensen B, Malm J, Carlberg B, Stegmayr B, Backman C, Fagerlund M, Olsson T: Epidemiology and etiology of ischemic stroke in young adults aged 18 to 44 years in northern Sweden. Stroke 1997, 28(9):1702-1709.

20. Lamy C, Giannesini C, Zuber M, Arquizan C, Meder J, Trystram D, Coste J, Mas J: Clinical and imaging findings in cryptogenic stroke patients with and without patent foramen ovale the PFO-ASA study. Stroke 2002, 33(3):706-711.

21. Kissela BM, Khoury JC, Alwell K, Moomaw CJ, Woo D, Adeoye O, Flaherty ML, Khatri P, Ferioli S, La Rosa FDLR: Age at stroke temporal trends in stroke incidence in a large, biracial population. Neurology 2012, 79(17):1781-1787.

22. Furlan AJ, Reisman M, Massaro J, Mauri L, Adams H, Albers GW, Felberg R, Herrmann $\mathrm{H}$, Kar S, Landzberg M, et al: Closure or medical therapy for cryptogenic stroke with patent foramen ovale. N Engl J Med 2012, 366(11):991-999.

23. Carroll JD, Saver JL, Thaler DE, Smalling RW, Berry S, MacDonald LA, Marks DS, Tirschwell DL: Closure of patent foramen ovale versus medical therapy after cryptogenic stroke. N Engl J Med 2013, 368(12):1092-1100.

24. Meier B, Kalesan B, Mattle HP, Khattab AA, Hildick-Smith D, Dudek D, Andersen G, Ibrahim R, Schuler G, Walton AS, et al: Percutaneous closure of patent foramen ovale in cryptogenic embolism. N Engl J Med 2013, 368(12):1083-1091.

25. Agarwal S, Bajaj NS, Kumbhani DJ, Tuzcu EM, Kapadia SR: Meta-analysis of transcatheter closure versus medical therapy for patent foramen ovale in prevention of recurrent neurological events after presumed paradoxical embolism. JACC Cardiovas Intervent 2012, 5(7):777-789.

26. Kitsios GD, Dahabreh IJ, Abu Dabrh AM, Thaler DE, Kent DM: Patent foramen ovale closure and medical treatments for secondary stroke prevention: a systematic review of observational and randomized evidence. Stroke I Cereb Circulation 2012, 43(2):422-431.

27. Moher D, Liberati A, Tetzlaff J, Altman DG, Group P: Preferred reporting items for systematic reviews and meta-analyses: the PRISMA statement Ann Int Med 2009, 151(4):W264-269.

28. Ford MA, Reeder GS, Lennon RJ, Brown RD, Petty GW, Cabalka AK, Cetta F, Hagler DJ: Percutaneous device closure of patent foramen ovale in patients with presumed cryptogenic stroke or transient ischemic attack: the Mayo Clinic experience. JACC Cardiovasc Intervent 2009, 2(5):404-411.

29. Heinisch C, Bertog S, Wunderlich N, Majunke N, Baranowski A, Leetz M, Fischer E, Staubach S, Zimmermann W, Hofmann I, et al: Percutaneous closure of the patent foramen ovale using the HELEX(R) Septal Occluder: acute and long-term results in 405 patients. Eurolntervent J EuroPCR Collabor Working Group Intervent Cardiol Euro Soc Cardiol 2012, 8(6):717-723.

30. Li Y, Zhou K, Hua Y, Wang C, Xie L, Fang J, Rong X, Shen J: Amplatzer occluder versus CardioSEAL/STARFlex occluder: a meta-analysis of the efficacy and safety of transcatheter occlusion for patent foramen ovale and atrial septal defect. Cardiol Young 2013, 23(4):582-596.

31. Sievert H, Wunderlich N, Reiffenstein I, Ruygrok P, Grube E, Buellesfeld L, Meier B, Schofer J, Muller D, Jones RK, et al: Initial clinical experience with the Coherex Flatstent and Flatstent EF PFO closure system for in-tunnel PFO closure: results of the Coherex- EU study. Catheter Cardiovasc Interv 2012. doi:10.1002/ccd.24565. [Epub ahead of print].

32. Stanczak LJ, Bertog SC, Wunderlich N, Franke J, Sievert H: PFO closure with the Premere PFO closure device: acute results and follow-up of 263 patients. Eurolntervention: I EuroPCR Collabor Working Group Intervent Cardiol Euro SoC Cardiol 2012, 8(3):345-351.

33. Wahl A, Juni P, Mono ML, Kalesan B, Praz F, Geister L, Raber L, Nedeltchev K, Mattle HP, Windecker $\mathrm{S}$, et al: Long-term propensity score-matched comparison of percutaneous closure of patent foramen ovale with medical treatment after paradoxical embolism. Circulation 2012, 125(6):803-812.

doi:10.1186/1471-2261-13-116

Cite this article as: Riaz et al:: Transcatheter patent foramen ovale closure versus medical therapy for cryptogenic stroke: a meta-analysis of randomized clinical trials. BMC Cardiovascular Disorders 2013 13:116.

\section{Submit your next manuscript to BioMed Central and take full advantage of:}

- Convenient online submission

- Thorough peer review

- No space constraints or color figure charges

- Immediate publication on acceptance

- Inclusion in PubMed, CAS, Scopus and Google Scholar

- Research which is freely available for redistribution 